\title{
Antibacterial Activity of Hybanthus Enneaspermus against Enterococcus Faecalis - A Root Canal Organism
}

\author{
Kalepu Vamsi*, Pradeep Kumar Bholla \\ Department of Prosthetic Dentistry, Penang International Dental College, Penang, Malaysia \\ *Corresponding author: drkvamsi@gmail.com
}

Received October 12, 2014; Revised November 23, 2014; Accepted December 21, 2014

\begin{abstract}
The root canal microbes which are responsible for the pulpal diseases have been attempted to be eliminated using various chemical methods. Herbal remedies used in folk medicine provide an interesting and still largely unexplored source for the creation and development of potentially new drugs for chemotherapy. This has been one such attempt aimed at testing the antimicrobial efficacy of Hybanthus enneaspermus, a herbal extract against the most resistant bacteria of the root canal system E.faecalis. This was done using microbiological agar diffusion test which concluded a good inhibiting effect of the aqueous herbal extract on the root canal organism, thus confirming its possible use as a root canal irrigant.
\end{abstract}

Keywords: Enterococcus faecalis, Hybanthus enneaspermus, root canal irrigant

Cite This Article: Kalepu Vamsi, and Pradeep Kumar Bholla, "Antibacterial Activity of Hybanthus Enneaspermus against Enterococcus Faecalis - A Root Canal Organism.” International Journal of Dental Sciences and Research, vol. 2, no. 6C (2014): 14-16. doi: 10.12691/ijdsr-2-6C-4.

\section{Introduction}

Microorganisms have a critical role to play in the etiology of pulpal and periodontal diseases, [1] and so their control and eradication are very essential during endodontic treatment [2].

Research work investigating the dynamics of root canal infections of teeth with failed endodontic treatment have described a small conglomeration of microorganisms, with predominantly facultative anaerobic gram positive species, especially E.faecalis. [3] Despite the fact that Enterococcus sp. barely contribute to the initial root canal flora of an untreated tooth [4] it has been considered one of the most resistant sp. and a possible reason for failure of root canal treatment [5].

It is therefore very essential to eliminate these microorganisms from the root canal system to treat the infections and to seal the tooth against re-infection to achieve a successful endodontic outcome. [6] One can abolish these microorganisms from root canals by using irrigating solutions during instrumentation and intracanal medicaments. [7] Formocresol, hydrogen peroxide, camphoratedmonochlorophenol, ethylenediaminetetraacetic acid, metacresylacetate, and sodium hypochlorite are the various root canal irrigants, used in endodontic procedures. Sodium hypochlorite is currently the preferred irrigant to disinfect and remove procedural debris from the root canal space. However, it has an unpleasant taste, is toxic in high concentrations, and has a limited bactericidal spectrum. Recently, chlorhexidine gluconate (CHX) has also been introduced as a root canal irrigant [6].

Even in this modern era, the developing countries are still relying immensely on traditional medicine to cover their basic health needs. Furthermore, in recent years the developed countries also have shown great interest in the use of herbal remedies. Resultantly, plants continue to be a rich source of therapeutic agents contributing remarkably to the drug industry with a large number of phytochemical and biological studies being conducted all over the world. Therefore, it is of great interest to carry out a screening of these plants in order to validate their use in medicine [8].

Thus this study aims at evaluating the antimicrobial effects of extract of the herb Hybanthus enneaspermus, against the most resistant endodontic organism Enterococcus faecalis for its use as an intracanal irrigant.

\section{Materials and Methods}

To procure the herbal extract, dry fruit of Hybanthus enneaspermus was first ground into a coarse powder and then using an electronic balance was weighed into $5 \mathrm{gm}$, $15 \mathrm{gm}$, and 50gm amounts following which it was transferred into labeled bottles. Aqueous filtered extracts of these powders were then obtained using sterile, deionized distilled water which was added to the powder and allowed to soak for 48 hours at $4^{\circ} \mathrm{C}$ to derive respective concentrations of 5\%, 15\% and 50\%.

The antibacterial activity of this prepared herbal extract was evaluated against the microorganism - Enterococcus faecalis ATCC 14506 (Hi Media Laboratories Pvt. Ltd., Mumbai) using agar diffusion test. All procedures were performed in a laminar cabinet under aseptic conditions.

The ampoules of the freeze dried forms of the microorganisms were opened and the contents were added to nutrient broth, which was incubated at $37^{\circ} \mathrm{C}$ for 24 
hours. A sterile cotton swab was dipped in the nutrient broth and then inoculated on to the Muller Hinton agar plate which was incubated overnight at $37^{\circ} \mathrm{C}$.

Six wells of six mm diameter and two $\mathrm{mm}$ depth were punched in the agar plates, which were filled with one drop of the extract, repeating the same procedure for each concentration of the herbal extract. Sterile deionised distilled water was taken as the negative control and CHX was taken as positive control. The plates were incubated at $37^{\circ} \mathrm{C}$ for 48 hours, after which they were examined for the size of their inhibition zones produced around the specimens. The inhibition zones were calculated in millimeters using digital calipers on the underside of the plate, by taking an average of three measurements of the halo. The results were statistically analyzed using t-test difference of means.

\section{Results}

The negative control/deionised distilled water showed no inhibition zones at all. Whereas the positive control/CHX group showed a mean of $13 \mathrm{~mm}$ zones. In the experimental group the zone sizes increased with increase in concentration. Resultantly, 50\% concentration of the extract showed the maximum zone with a mean of $9 \mathrm{~mm}$, which was significantly less ( $p$-value $=0.000255$ ) than the CHX group.

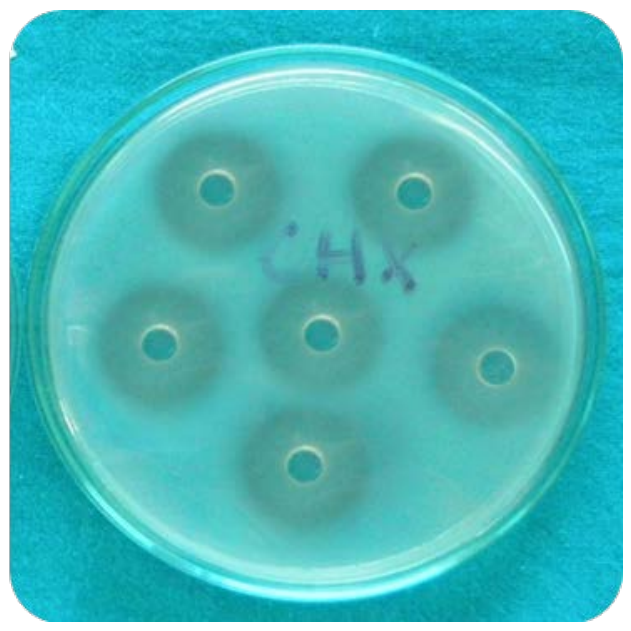

Figure 1. Inhibition zones of CHX (mean - 13mm)

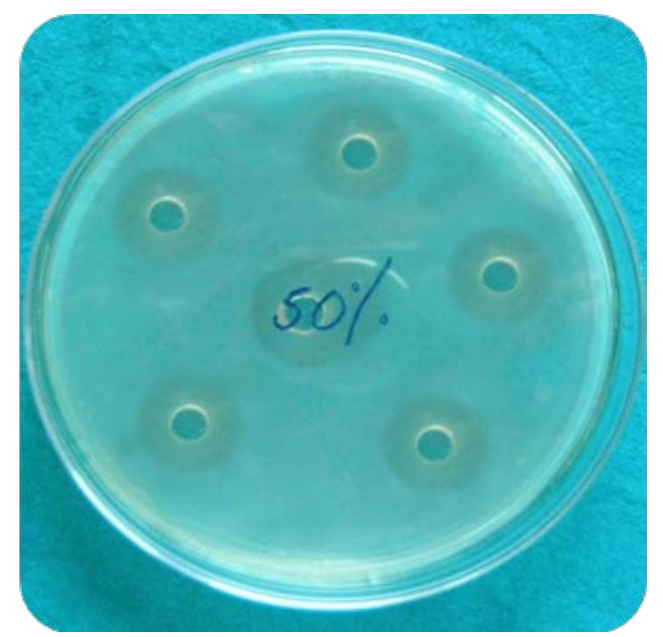

Figure 2. Inhibition zones of 50\% herbal extract (mean - 9 mm)

\section{Discussion}

Hybanthus enneaspermus Muell, belonging to family Violaceae, popularly known as Ratanpurus (Hindi) is herb or under shrub, seen in the tropical and subtropical regions of the world. [9] It has been reported to have antiinflammatory, [10] antitussive, [11] antiplasmodial, [12] anticonvulsant and free radical scavenging activity. [13] In folklore the plant is used in case of pregnant and parturient women, and in case of gonorrhoea and urinary infections. When this plant extract was tested for its antibacterial activity against selected E.faecalis of urinary tract, it showed significant effect in ethanol form and moderate effect in aqueous form.[9] Hence this herb was selected to test against the same organism which resides in the root canals also.

The plant is reported to contain aurantiamide acetate, isoarborinol, b-sitosterol and triterpene. [14] At 5\% and $15 \%$ concentration the herbal extract did not show any significant inhibition zone but at higher concentration of $50 \%$ a significant antibacterial effect was present inhibiting the microorganism E.faecalis. This effect could have been due to the presence of various components mentioned earlier. However, the positive control CHX showed a better zone of inhibition.

Scientific analysis of plant components follows a logical pathway. Initial screenings of plants for possible antimicrobial activities typically begin by using crude aqueous or alcohol extractions and can be followed by various organic extraction methods. [15] So in this research an attempt to screen the antibacterial efficacy of the plant in its aqueous form seemed successful, so further research may be required in other forms to prove more promising results.

\section{Conclusion}

The root canal irrigants currently available have some or the other drawbacks, so the search for a better irrigant continues. The use of herbal extracts in dentistry is not novel. This study tested aqueous herbal extract of Hybanthus enneaspermus against the most resistant root canal organism E.faecalis which could be inhibited significantly at $50 \%$ concentration. But it may be stated that with more specific extraction methods using other vehicles, the herb may prove to be a good intracanal irrigant, therefore any further investigations should work towards better methods of obtaining the extract.

\section{Statement of Competing Interests}

The authors have no competing interests.

\section{List of Abbreviations}

CHX - Chlorhexidine.

\section{References}

[1] Sundqvist G, "Ecology of the root canal flora," Journal of Endodontics, 18, 427-430, 1992 
[2] Valera MC, Rego JM, Jorge AOC, "Effect of sodium hypochlorite and five intracanal medications on Candida albicans in root canals,” Journal of Endodontics, 27, 401-8, 2001.

[3] Gomes BPFA, Pinheiro ET, Gade-Neto CR, Sousa ELR, Ferraz CCR, Zaia AA, Teixeira FB, Souza - Filho FJ, "Microbiological examinations of infected dental root canals," Oral Microbiology Immunology, 19, 71-76, 2004.

[4] Siqueira JF Jr1, Rôças IN, Souto R, de Uzeda M, Colombo AP, "Actinomyces species, streptococci, and Enterococcus faecalis in primary root canal infections,” J Endod., 28 (3), 168-72, Mar. 2002.

[5] Molander A1, Reit C, Dahlén G, Kvist T, "Microbiological status of root-filled teeth with apical periodontitis," Int Endod J., 31 (1), 1-7, Jan. 1998.

[6] Elaine Dang, "Comparison of Sodium Hypochlorite and Chlorhexidine Gluconate: Quality of Current Evidence,” Journal of Young Investigators, Volume 19, 2008.

[7] Menezes MM, Valere MC, Jorge AOC, Koga-Ito CY, Camargo CHR, Mancini MNG, "In vitro evaluation of the effectiveness of irrigants and intracanal medicaments on microorganisms within root canals," International Endodontic Journal, 37, 311-319, 2004.

[8] Kianbakht S, Jahaniani F, "Evaluation of Antibacterial Activity of Tribulus terrestris L. Growing in Iran,” Iranian Journal of Pharmacology and Therapeutics, 2 (1), 22-24, 2003.
[9] Sahoo S, Kar DM, Mohapatra S, Rout SP, Dash SK, "Antibacterial activity of Hybanthus enneaspermus against selected urinary tract pathogens" Indian J Pharm Sci, 68, 653-5, 2006.

[10] Boominathan R, Parimaladevi B, Mandal SC and Ghoshal SK, "Anti-inflammatory evaluation of Ionidium suffruticosam Ging. in rats," J. Ethnopharmacol, 91 (2-3), 367-70, Apr. 2004.

[11] Boominathan R, Parimaladevi B and Mandal SC, "Evaluation of antitussive potential of Ionidium suffruticosam Ging. (Violaceae) extract in albino mice," Phytotherapy Res., 17, 838-9, Aug 2003.

[12] Weniger B, Lagnika L, Vonthron-Senecheau C, Adjabimey D, Gbenou J, Moudachirou M, Brun R, Anton R and Sanni A, "Evaluation of ethnobotanically selected Benin medicinal plants for their in vitro antiplasmodial activity," J. Ethnopharmacol., 90 (2-3), 279, Feb. 2004.

[13] Hemlatha S, Wahi AK, Singh PN and Chansouria JPN, "Anticonvulsant and free radical scavenging activity of Hybanthus enneaspermus: A preliminary screening,"Indian J. Traditional Knowledge, 2 (4), 383-8, Oct. 2003.

[14] Cowan MM, "Plant Products as Antimicrobial Agents," Clinical Microbiology Reviews, 12 (4), 564-582, Oct. 1999.

[15] Majumdar PL, Basu A and Mal D, "Chemical constituents of Hybanthus enneaspermus,” Indian J. Chemistry, 17B, 297-8, 1979. 